\title{
Effect and Risk Analysis of New Rural Cooperative Medical System in Guizhou Province under big Data Environment
}

\author{
Yong-mei, $\mathrm{He}^{1,2}$ \\ Guizhou University of Finance and Economics \\ ${ }^{1}$ Institute of Finance, ${ }^{2}$ Guizhou Institute of Urban Economy \\ and Development \\ Guiyang City, Guizhou Province, China \\ 411740421@qq.com
}

\begin{abstract}
In September 2016, Guizhou Province started the full implementation of the new rural cooperative medical insurance policy. The coverage of NRCMS in the future will be more extensive and its development will be more rapid. As a result, the data of the disease insurance will increase in a faster manner, which is particularly important for the processing and utilization of data. In this paper, according to the current situation of the development of NCMS in Guizhou Province, the current situation of NCMS in Guizhou Province is analyzed. The results show that there are a series of risk problems in the implementation of NCMS, which are both external and internal. The risk put forward the corresponding solution. This paper argues that we should give full play to the advantages of the Internet and establish a unified information system of new rural cooperative medical insurance in the province. With the assistance of big data service platform, we will strengthen the risk control of new rural cooperative medical insurance in Guizhou Province and ensure the continuous and effective operation of new rural medical insurance.
\end{abstract}

Keywords-new rural cooperative medical insurance; running effect; big data; risk; countermeasure

\section{INTRODUCTION}

In recent years, with the medical insurance of urban residents and the basic coverage of new rural medical insurance covering all urban and rural residents, the basic medical insurance of the people has been guaranteed. However, due to the low relatively low level of basic medical insurance, high medical expenses still bring a heavy financial burden to the families when the people suffer from serious diseases. In the crucial period of building a well-off society in an all-round way and tackling hard-fought hardships in poverty relief in our country, the State Department has attached great importance to the phenomenon of poverty due to illness and poverty caused by many families. The formulation and implementation of the new rural cooperative medical insurance policy provides a very important guarantee for the urban and rural residents' medical insurance. In recent years, the implementation of new rural cooperative insurance in the provinces of the whole country has achieved remarkable results, and the benefits of the insurance system have been enjoyed by local residents.

\author{
Hong-mei,Zhang ${ }^{1,2}$ \\ Guizhou University of Finance and Economics \\ ${ }^{1}$ Institute of Finance ${ }^{2}$ Guizhou Institute of Urban Economy \\ and Development \\ Guiyang City, Guizhou Province \\ 2569055506@qq.com
}

Since 2013, to lighten the burden of illness of urban and rural residents in guizhou, positive response national policy, to carry out the implementation of the new farmers and serious illness insurance policy, the development of new farmers and serious illness insurance has achieved significant results. The establishment of NRCMS sickness insurance is to solve the problem of "disease causing poverty and returning to poverty". As of the end of February 2016, Guizhou province has fully covered the coverage of the NRCMS, covering an area of 33 million people. The level of protection is at a relatively high level throughout the country. However, the actual compensation rate is only $65 \%$ serious illness, medical expenses may still lead to poverty due to illness, return to poverty due to illness.

\section{Operation StATUS AND Risk ANALYSiS OF NEW RURAL COOPERATIVE MEDICAL INSURANCE IN GUIZHOU PROVINCE}

A. The current situation of insurance operation of new rural and major diseases in guizhou province

\section{1) Operation plan.}

a) Fund raising. The sources of funds for the NRCMS in Guizhou follow the Guiding Opinions. Capital from the Medicare and NRCMS balances is set at a certain percentage and the deficit area is raised as an overall solution during the annual increase in funding. Residents do not need to pay extra money to meet the needs of medical insurance. The new farming and serious illness insurance fund-raising standard in guizhou is allocated in proportion, namely according to the certain proportion of the health care financing standard transfer, this way is closely related to raise the fund of insurance of primary medical treatment. Currently, the standard of insurance financing for major diseases in guizhou province is at a lower level nationwide.

b) The overall level. The low level of overall coordination will hinder the dispersion effect of the serious illness insurance, affect the efficiency of the swap funds and reduce the fairness of the system. Therefore, the urban-rural resident 
illness insurance in Guizhou Province is still dominated by the city-level co-ordination.

c) To protect the object. At present, Guizhou Province, with reference to the "Guiding Opinions," identified the object of protection for serious illness as the insured (syndicate) of urban residents and NCMS. Moreover, guizhou province has already incorporated the newborn into the protection of major disease insurance, which reflects the humanistic side of the system.

d) Coverage. The scope of coverage of Guizhou Province's major illness insurance is based on the "Guiding Opinion," that is, in the case of serious illness in patients with high medical costs, after deducting the insurance part of the basic medical insurance, still need personal burden of compliance medical costs over the serious illness insurance Of the starting line, they will be given protection. The high medical costs vary according to the level of economic and social development in various places. The various areas are dynamically adjusted according to the actual conditions of that year. The compliance medical expenses refer to "the actual medical expenses incurred in line with the medical treatment norms, necessary for treatment, and reasonable medical expenses."

e) The level of protection. Currently, Guizhou Province has not made a specific starting line, that is, the annual per capita disposable income of urban residents is not higher than that of the previous year and the per capita net income of rural residents is reasonably determined. From the top of the summit, guizhou province directly stipulates that the insurance expense reimbursement for urban and rural residents is "not peak"; From the perspective of payment ratio, Guizhou Province refers to the "Guiding Opinion" requirement, stipulating that the actual payment proportion of serious illness insurance should be not less than $50 \%$, and should be paid in accordance with the level of medical expenses in stages, that is, the higher the medical expenses, the higher the proportion of payment .

\section{2) Implementation Effect}

Since 2013, the implementation of NCMS in Guizhou Province has achieved remarkable results. Until the end of December 2015, Guizhou Province, according to the promulgation of specific implementation plans issued by various aspects of new rural cooperative medical insurance compensation work, the province has a total of 136000 accounting for the masses to enjoy a serious illness insurance compensation, compensation funds of 728 million yuan, after the combination of NCMS fund compensation and serious illness insurance policy is implemented, the actual compensation proportion of insured persons reaches about 72\%.In 2016, the cost of reimbursement for in-patient reimbursement for urban resident illness insurance in Qiandongnan Prefecture dropped from RMB 50,000 to RMB 6,000. At present, 272,700 people insured in Qiandongnan Prefecture, a fixed-point medical institutions co-ordination fund payment ratio increased from $80 \%$ to $90 \%$, two fixedpoint medical institutions co-ordination fund payment ratio from the original $70 \%$ to $80 \%$, three Fixed-point medical institutions co-ordinate fund payment ratio from the original $60 \%$ to $65 \%$; The maximum payment limit for the basic medical insurance fund for urban and rural residents will be raised from 50,000 yuan to 200,000 yuan. Urban residents sickness insurance hospital reimbursement level, more than the standard part of the payline 1-10000 yuan 50\% of the compensation, 10001-30000 yuan 60\% of the compensation, more than 30001 yuan $80 \%$ of claims, the occurrence of compliance medical expenses Major illness insurance fund actually paid Proportion of not less than 50\%; The maximum payment limit for urban residents will be raised from 100,000 yuan to 500,000 yuan. Since Jianhe County implemented the new rural cooperative medical insurance in 2016, a total of 42,222 aid recipients were identified in Jianhe County, of which 2854 were confirmed as "two households" and those with loss of independence families, and 1474 were found to have severe disability. The number of civil affairs departments 38294 people, entered the maintenance of new rural cooperative medical information system 6209 people, funded a total number of 20533 people 101.425 million yuan, 11 kinds of precise poverty alleviation aid review 6,027,800 yuan 621,800 yuan, civil administration, family planning medical assistance 61 people 165,600 yuan. Since the implementation of the new rural cooperative medical insurance in Dajiang County and Jinping County, the level of medical security has been obviously improved. The three aspects are as follows: First, the NCMS participation rate has obviously improved; secondly, the compensation for serious illness has been obviously raised; thirdly, the serious illness insurance helps push forward the effective implementation of the project of helping the poor and the healthier people in poverty alleviation. Through the survey also found that Liupanshui, Dafang County, Majiang County, Suiyang County and other regions increased the level of NCMS security, and the masses have gained real benefits. The evaluation of NCMS major illness insurance is generally better.

\section{B. Risk Analysis of New Rural Cooperative Insurance System in Guizhou Province}

Since the implementation of NCMS in Guizhou Province, NCMS has developed rapidly within the province and coverage has been gradually expanded. More and more people have become an indispensable part of the medical insurance system in the province. In recent years, great achievements have been made in the implementation of the new rural cooperative medical insurance system. With the continuous advancement and deepening of the new rural medical insurance system, the data of the participating targets are constantly increasing, and the NRCMS is gradually becoming more and more large, The key points for the construction of health informatization in all regions also gradually changed from initial network construction and single system construction to the construction of large-scale regional medical information systems and largescale data centers. From the current situation, Guizhou Province, the implementation of new rural cooperative medical insurance risks mainly includes external risks and internal risks 
of two types. This article conducted a brief analysis of the above two risks as follows:

1) External risks. Currently, the main external risks facing Guizhou's implementation of NCMS insurance are: the rising medical demand, the risks of fund raising and use, the moral hazard and the risks in the formulation and implementation of policies. Rising in recent years, an aging population, according to the survey of China's ageing population status quo and development trend forecast report (2017), in 2016 China's total population of 1.36 billion people more than 60 elderly population, 210 million, in a long time in the future in our country are faced with the aging of the population problem. At present, the pension security system in our country is still not perfect. Therefore, the unfortunate illness of peasants in their old age may lead to the paralysis of the family economy at any time. With the continuous improvement of people's living standards, due to food safety, ecological environment are not well protected, resulting in the breeding of many diseases, in recent years, due to water, air, food and other issues lead to infectious diseases, malignant tumors, Cases of cancer emerge in an endless stream. Due to the current state of Guizhou Province NCMS insurance system used to raise funds for the fund. Funds are a category of financial products that pose a number of risks in fund raising, balances and payment.

2) Internal risks. The internal insurance in the implementation of NCDMS insurance mainly refers to the internal management risk of insurance companies. In the event of a risk, the insurance business often involves medical regulators, insurers and governments. As China's medical insurance system is still in a state of continuous improvement, medical and insurance services can not reach a complete harmonization. At present, patients are required to pay the medical fee before they go to the insurance reimbursement process before they can receive insurance compensation. This approach is often prone to moral hazard. For insurance companies, management costs and the fair premium is corresponding to the key factors influencing the insurance company accept insurance serious illness insurance, fair premium refers not only to the insurance company is willing to provide a sufficient funds claim cost and management cost, also can have extra profit premiums. When the cost of operation and management of an insurance company is higher than the fair premium, there will be serious internal risks to the commercial insurance institutions.

\section{COUNTERMEASURES AND SUGGESTIONS ON THE RISK CONTROL OF NRCMS IN GUIZHOU UNDER BIG DATA ENVIRONMENT}

In recent years, big data technology has developed rapidly, and the application of big data in various industries has been paid more and more attention. Because data is a very important asset, data resources can be processed through big data technology, and the potential value of data can be mined. In recent years, the rapid development of new rural cooperative medical insurance, which participate in the information gradually increased, and establishing a sound medical insurance information and information system is conducive to improving the operational efficiency of new rural cooperative medical insurance. Rational use of big data technology in the NCMS "risk control" will provide a more powerful guarantee for the efficient and orderly operation of NCMS. Using big data to control the risk of new rural cooperative medical insurance, this paper made the following policy recommendations:

\section{A. Using big data platforms to raise capital and reduce the risk of financing}

Through the use of big data platform, NCMS insurance policies can be widely publicized to achieve data sharing and reduce information asymmetry. Make more people participate in the new rural cooperative medical insurance. Through big data technology, we can set up a unified basic database for the probability of occurrence of serious illness insurance and medical expenses, to actuat actuarial pricing for serious illness insurance through the database. We set reasonable premiums and claims settlement programs and set up a reasonable basic medical insurance for financing the serious illness insurance. Standarding linkage adjustment mechanism for the funding criteria for serious illness insurance to set a reasonable adjustment of space and effectively control the funding risk of serious illness risks.

\section{B. Using big data to implement detailed management and guard against business risks}

The application of big data technology can realize the omnidirectional management of the insured person, insurance information and policy. Big data technology can be used to classify the insured persons, classify the insured persons according to the information about the insured's health, occupation and other related information, and then carry out classification management so that the insurer can predict the probability of occurrence of the insured person's risk. Risky customers timely design other value-added services. In addition, through big data technology, we can know the adjustment mechanism of profit and loss of major illness insurance. Through comprehensive analysis of medical expenses, insurance policies and market environment, timely adjustment of operating plans can effectively reduce operational risks.

\section{Using big data to strengthen credit administration and control moral hazard}

The use of big data platform to establish and improve the serious illness insurance information system, unified management of information, including insurance companies, the insured person information, medical institutions, serious illness insurance policies and other information updated in real time. Through the information platform, we can carry out investigation and inquiry on the information of serious illness insurance at any time to achieve social supervision. 
D. Using big data to establish early warning system for major illness insurance

The establishment of a new rural cooperative medical insurance risk early warning system, the use of big data technology can be updated in real time data, according to the insured person information, policies, market environment changes, timely updates, and through data analysis tools to measure the various risk states, and risk Early warning system through the establishment of risk index system, analysis of factors that affect the risk changes in order to control the risk in a timely manner.

\section{CONCLUSION}

With the continuous improvement of the medical insurance system, NCMS insurance has gradually become an indispensable part of medical insurance. However, the risks of NCMS insurance in operation will also be relatively increased, which in turn will undoubtedly increase the risks of insurance companies, governments and patients. In order to effectively control the risks in the operation of health insurance, this paper argues that big data technology should be used to establish a unified database and analyze and deal with the increasing data. This will help to improve the operation and management level of insurance companies and ensure that government policies and measures will benefit the seriously ill and effectively ensure the level of urban-rural medical insurance.

\section{ACKNOWLEDGEMENT}

The successful completion of this thesis is inseparable from the support and help of Insurance workstations of Guizhou University of Finance and Economics School of Finance. Thank you very much for teachers who helped me. As the process of completion, the level of personal theory is limited, the literature found in the lack of information, some of the views of the paper and the policy recommendations for precision poverty alleviation in China will inevitably have omissions and shortcomings, welcome teachers and experts correct.

\section{REFERENCES}

[1] Gu Xin,A Study on Fund Balance of Urban and Rural Public Health Insurance in China,J,Journal of Chinese Academy of Social Sciences. May 2010.

[2] Xiaoyue Chen, Development bottleneck and countermeasure of new rural cooperative medical insurance, J, Introduction to Economic Studies, 2014(7):90-95.

[3] Wenqun Li, Talking about the Pricing of China 's Serious Illness, J, Introduction to Economic Studies, 2013(16): 166-168.

[4] Yulin Chou and Guowu Huang, Research on the Transformation of Medical Security System in China, J. Insurance Research, 2013(8):108119.

[5] Minglai Zhu, Zhanjun Song and Wang Xin, Reflections on the Mode of Compensation for Serious Illness - An Empirical Analysis Based on the Data of New Rural Cooperative Hospital in, J. Insurance Researc.2013(1):97-105.

[6] JoyceB, LauD. MedicarePart DprecriptionDrugBenefit: An Update[EB/OL]. 2012-12-06. http://www.aging. northwestern. Edu/media/pdf/22_2.pdf 